\title{
Carbide formation in tungsten coatings on carbon-fibre reinforced carbon substrates
}

\author{
M. Rasinski1*, H. Maier2, C. Ruset3, M. Lewandowska1, K. J. Kurzydlowski1
} 1Faculty of Materials Science and Engineering, Warsaw University of Technology, ul. Wołoska 141, 02-507 Warsaw, Poland

2Max-Planck-Institut für Plasmaphysik, EURATOM Association, Boltzmannstraße 2, D85748 Garching, Germany

3National Institute for Laser, Plasma and Radiation Physics, EURATOM-MEdC Association, Str. Atomistilor 409, 077125 Magurele, Bucharest, Romania

\section{$\underline{\text { Abstract }}$}

Tungsten coatings with molybdenum interlayer deposited on carbon-fibre reinforced carbon (CFC) substrates were selected as the first wall material for the divertor in the ITERlike Wall Project at Joint European Torus. For such a layered structure, diffusion of carbon from the CFC substrate towards the Mo and W deposits is expected during the operation of the reactor. As both molybdenum and tungsten form stable carbides, brittle compounds may form at the interface, thus strongly affecting the thermomechanical performance of the coated tiles. For the purpose of prediction of the operation time of such coated tiles, carbon diffusion and carbide formation kinetics need to be determined.

In the present study, W/Mo/CFC samples were subjected to heat treatment at $1470 \mathrm{~K}$ for various annealing times. The Focused Ion Beam technique was used for sample preparation for electron microscopy examinations. Transmission electron microscopy observations supported with diffraction pattern analyses revealed the both $\mathrm{W}_{2} \mathrm{C}$ and $\mathrm{WC}$ carbides in the $\mathrm{W}$ coating, as well as that of $\mathrm{Mo}_{2} \mathrm{C}$ carbide in the Mo layer. The results were used to estimate the kinetics of coatings degradation. 
Keywords: tungsten carbides precipitation, molybdenum carbide precipitation, carbon diffusion, electron diffraction, TEM, degradation of plasma facing components.

\section{Introduction}

The development in nuclear fusion science began in the 1950s and is since than under constant progress. The next step on the road to fusion power plant is the International Thermonuclear Experimental Reactor (ITER) project whose main scientific goal is to deliver ten times the power it consumes [1] - and the first of all fusion experiments to produce net energy. During the first operation period of the ITER reactor according to the current design plasma facing components shall be made of beryllium (on the first wall) and of tungsten and carbon-fibre reinforced carbon (CFC) (in the divertor) [2]. Further operation of ITER, including the use of tritium as a fuel, might require a full $\mathrm{W}$ divertor [3]. However, so far there is no available data on the performance of this materials combination in a fusion environment. For that purpose the ITER-like Wall Project was launched at Joint European Tokamak with the goal to test this materials combination at the most ITER-relevant parameters accessible today [4-6]. In the current ITER-like wall project, tungsten lamellae stacks are installed in the load-bearing septum replacement plate and $\mathrm{W}$ coatings on CFC in the other divertor regions [7].

In order to verify feasibility of using $\mathrm{W}$ coatings, various coating techniques were investigated in a coordinated R\&D program launched in 2005 [8-10]. As a result of this program 10-15 $\mu \mathrm{m}$ thick $\mathrm{W}$ coatings with 2-4 $\mu \mathrm{m}$ Mo interlayer produced by combined magnetron sputtering and ion implantation (CMSII) technique were selected as the most reliable [11]. Later, in 2009 this technique was modified to produce $20-25 \mu \mathrm{m} \mathrm{W}$ coatings. 
These technological achievements need to be supplemented with a proof of thermal stability of the W coatings on a carbon-rich substrate, particularly because no carbon diffusion barrier is foreseen in the present coatings concept. At the same time a strong effect of the tungsten carbides formed via precipitation driven by the carbon diffusion on the thermo-mechanical properties of the coatings has been observed [12]. In this context, the main motivation of this work was to investigate the carbide formation in these Mo/W coatings on CFC substrates exposed to high temperatures in a model laboratory environment. It has been assumed that such investigations shall provide estimates of the carbon diffusion rate in such a particular system and thus, in turn, of the safe operation time of such coated tiles.

\section{Experimental details}

Bi-directional CFC substrates were coated with 2-4 $\mu \mathrm{m}$ molybdenum interlayer and subsequently $10 \mu \mathrm{m}$ tungsten film. The deposition was carried out by CMSII technology at the National Institute for Laser, Plasma and Radiation Physics in Bucharest. A detailed description of the process is given elsewhere [11].

Coated samples with dimensions $10 \times 10 \times 3 \mathrm{~mm}$ were annealed at $1470 \mathrm{~K}$ for $0.5 \mathrm{~h}, 1 \mathrm{~h}$, $2 \mathrm{~h}, 5 \mathrm{~h}$ and $20 \mathrm{~h}$ under Argon atmosphere (the furnace was purged with Ar three times at room temperature and three times at $670 \mathrm{~K}$ ) to avoid tungsten oxidation during annealing. Each sample was enveloped with a thin tungsten foil to eliminate possible contact with carbon. In order to estimate the kinetics of carbon diffusion from the CFC substrate to the $\mathrm{W}$ coatings, measurements were carried out of the thickness of tungsten carbides formed as a result of the annealing. To this end, cross sections were prepared and observed using a FEI Helios NanoLab 600 dual beam - focused ion beam/scanning electron microscopy 
(FIB/SEM). Since in the FIB/SEM dual beam column is at an angle of $52^{\circ}$ to the sample surface, a correction factor was used equal $1 / \cos \left(38^{\circ}\right)$. The platinum protection coating was deposited using $0.92 \mathrm{nA}$ beam current for $7 \mathrm{~min}$. The cross-sectioning was performed in a three step process - rough cross-section milling with maximum current of $21 \mathrm{nA}$, and two subsequent cleaning millings with ion current of $6.5 \mathrm{nA}$ and $0.92 \mathrm{nA}$, respectively.

The mass contrast in the SEM was used to distinguish between tungsten and tungsten carbide in individual SEM images. The carbide phase composition was determined by nano diffraction in Hitachi HD-2700 Cs corrected dedicated STEM equipped with $200 \mathrm{kV}$ Schottky electron source. STEM observations were carried out on thin lamellas prepared by the FIB lift out method.

To determine the degradation of coating's mechanical properties due to brittle carbide formation, a micro scratch test was performed using REVETEST Scratch Testing instrument equipped with $200 \mu \mathrm{m}$ diamond ball as an indenter. Applied load was linearly increasing from $1 \mathrm{~N}$ to $6 \mathrm{~N}$ with the indenter sliding rate $0.05 \mathrm{~mm} / \mathrm{s}$. A critical load to coating's failure was measured. In all cases, after the micro-scratch test a FIB cross-sections were prepared near the failure area and a SEM was performed.

\section{Results and the Discussion}

The microstructure of $\mathrm{CFC} / \mathrm{Mo} / \mathrm{W}$ coatings as a function of annealing time is shown as SEM cross sections in Figure 1. It can be noted that the as-deposited coating before the annealing consists of two layers:

(1) $4.0 \pm 0.9 \mu \mathrm{m}$ thick Mo

(2) $12.7 \pm 1.2 \mu \mathrm{m}$ thick $\mathrm{W}$ 
(see Fig. 1a).

As seen in Figure 1b in conjunction with Figure 2, after $0.5 \mathrm{~h}$ of annealing the Mo layer fully transforms into $\mathrm{Mo}_{2} \mathrm{C}$. Also a thin interlayer of between $\mathrm{Mo}_{2} \mathrm{C}$ and $\mathrm{W}$ is formed. It is continuous but of variable thickness ranging from 300 to 2320 nanometers.

Observations on the samples subjected to a longer annealing, for $1 \mathrm{~h}$ and $2 \mathrm{~h}$, revealed that the interlayer between $\mathrm{Mo}_{2} \mathrm{C}$ and $\mathrm{W}$ increases its thickness. Additionally, in some places another interlayer starts to develop, as illustrated in Fig. 1c, d. After $5 \mathrm{~h}$ of annealing, this second interlayer becomes geometrically continuous, with the thickness varying from 1.2 to $2.4 \mu \mathrm{m}$ (Figure 1e).

The interlayer formed during 30 minutes annealing at $1470 \mathrm{~K}$ has been identified based on the diffraction patterns and STEM investigations, as illustrated in Fig. 2. It was found that already after annealing for 30 minutes at $1470 \mathrm{~K}$ Mo fully transforms into $\mathrm{Mo}_{2} \mathrm{C}$ (hexagonal, P63/mmc) carbide, as supported by the diffraction pattern in Fig. 2. For 30 min annealing time also a thin $\left(1.2 \mu \mathrm{m}\right.$ in thickness) layer of $\mathrm{W}_{2} \mathrm{C}$ (hexagonal, $\left.\mathrm{P} 63 / \mathrm{mmc}\right)$ carbide has been identified. At the same time there was no evidence of the presence of WC type carbide.

After annealing for $20 \mathrm{~h}$, the thickness of $\mathrm{W}_{2} \mathrm{C}$ is close $1.1 \mu \mathrm{m}$ while total carbide thickness is close to $4.4 \mu \mathrm{m}$. Additionally, WC (hexagonal, P-6m2) carbide phase has been found. In all samples $\mathrm{W}_{2} \mathrm{C}$ carbide phase forms columnar grains which grow and coarsen with the increasing annealing time. Their length increases from 340 to $1020 \mathrm{~nm}$ and their width from 120 to $340 \mathrm{~nm}$.

As mentioned earlier, the first WC carbides appear after $1 \mathrm{~h}$ of annealing, however, for annealing times below $5 \mathrm{~h}$ it appears only locally. After $5 \mathrm{~h}$ annealing the thickness of WC layer is about $2 \mu \mathrm{m}$ whereas total tungsten carbide reaches $3.2 \mu \mathrm{m}$. 
Heat treatment at $1470 \mathrm{~K}$ for $20 \mathrm{~h}$ results in $3.3 \mu \mathrm{m} \mathrm{WC}$ carbide interlayer. At the same time the total thickness of the carbide interlayer, i.e. $\mathrm{WC}+\mathrm{W}_{2} \mathrm{C}$ reaches $4.4 \mu \mathrm{m}$. This means that almost half of the initial $\mathrm{W}$ coating transforms into carbide phase after $20 \mathrm{~h}$ of annealing. Additionally in Fig. 1a, b, f specific elongated voids structure inside the W coating is visible. Their formation during the deposition process results from the surface roughness.

The thickness of $\mathrm{WC}$ carbide layer and the total thickness of $\mathrm{W}_{2} \mathrm{C}+\mathrm{WC}$ as a function of annealing time are shown in Figure 3. In the case where the pertinent layer is not continuous the average thickness over the measured islands is being plotted. The data presented in Fig. 3 show that the growth of both layers $\left(\mathrm{WC}\right.$ and $\left.\mathrm{WC}+\mathrm{W}_{2} \mathrm{C}\right)$ follow different kinetics.

The results presented in this report give a clear picture of the phase transformations taking place during annealing of the $\mathrm{W}+$ Mo coatings deposited on CFC substrates.

It should be noted that first the $\mathrm{W}_{2} \mathrm{C}$ phase forms at the interface of $\mathrm{W}-\mathrm{Mo}_{2} \mathrm{C}$. It precedes the formation of WC because of its lower equilibrium concentration of $\mathrm{C}$ which equals 3 wt.\% whereas in the case of WC it is $6.12 \mathrm{wt} . \%$ [13]. For the longer annealing times, when the $\mathrm{C}$ concentration in $\mathrm{W}_{2} \mathrm{C}$ builds-up it starts into the $\mathrm{WC}$ phase, which is more stable because of the lower free energy, as calculated in [14].

It should be noted that the WC appears at the interface $\mathrm{Mo}_{2} \mathrm{C} / \mathrm{W}_{2} \mathrm{C}$ in the form of islands, which increase their size with annealing time, finally forming a continuous layer. This type of WC nucleation, also reported in $[15,16]$, suggest that the energy of the WC-W interface is higher preventing the islands from forming a continuous layer in the early stage.

Based on the results presented here also some useful information about the growth mechanism can be derived from the simple relation between the carbide phase thickness $d$ and the annealing time $t$ :

$$
d=D \cdot t^{n}
$$


where $D$ is growth rate constant and $n$ is the exponential factor. When $n$ is close to 1 the process is controlled by the reaction rate. If the growth is controlled by volume diffusion then $n$ is close to 0.5 [17-18]. In the case of total carbides layer, the value of exponential factor $n$ equals to 0.4 which being close to 0.5 indicates the volume diffusion is a predominant factor determining growth kinetics. The situation is different in the case of WC carbide, where the exponential factor $n$ is close to 0.9 , which indicates the reaction at the $\mathrm{W}_{2} \mathrm{C} / \mathrm{WC}$ interface as the limiting growth rate factor.

Fig. 4 illustrates SEM images of CFC/Mo/W cross-sections before and after annealing. In each image, the value of critical force to coating's failure is provided. In the case of sample before annealing, no failure was observed, even at the maximum force of 6 N. However, some cracks perpendicular to the surface are present in the coating. First failure of the coating occurs after $2 \mathrm{~h}$ of annealing, at a critical force of $5.2 \mathrm{~N}$. Further increase in the thickness of the carbide phase results in a decrease of the critical force to failure to $4.5 \mathrm{~N}$ and $4.1 \mathrm{~N}$ for sample annealed for $5 \mathrm{~h}$ and $20 \mathrm{~h}$, respectively. First cracks start to be visible in the carbide layer in the sample annealed for $2 \mathrm{~h}$ at $1470 \mathrm{~K}$, and more pronounced in the sample annealed for longer limes. The thicker the formed carbide layer the more pronounced cracking is observed and by that lower critical force is required for the coatings to fail. Strong influence of annealing time and by that of tungsten carbide layer formation on the coating's mechanical properties was confirmed.

\section{4. $\underline{\text { Conclusions }}$}

This work provides an insight into the transformations of W/Mo coatings deposited on CFC substrates into carbides stimulated by exposure to high temperatures. SEM and TEM studies analysis revealed that upon annealing at $1470 \mathrm{~K}$, the initial Mo layer fully transforms 
into $\mathrm{Mo}_{2} \mathrm{C}$ carbide already after $30 \mathrm{~min}$. In the prior tungsten coating two tungsten carbide interlayers develop, identified as $\mathrm{W}_{2} \mathrm{C}$ and $\mathrm{WC}$. The $\mathrm{W}_{2} \mathrm{C}$ interlayer forms already after 30 minutes. Annealing for $1 \mathrm{~h}$ and $2 \mathrm{~h}$ leads to local precipitation of $\mathrm{WC}$ islands, indicating that carbon diffusion may vary depending on the local substrate morphology. A continuous WC layer forms after $5 \mathrm{~h}$ annealing and its thickness increases with time. The total $\mathrm{WC}+\mathrm{W}_{2} \mathrm{C}$ layer growth rate is controlled by diffusion whereas the WC phase growth rate is controlled by the reaction rate.

Additionally, a micro-scratch test confirmed the degradation of the coating's mechanical properties due to brittle carbide formation. With increased thickness of the carbide phase, the critical force to coating failure has decreased reaching $4.1 \mathrm{~N}$ for sample after $20 \mathrm{~h}$ of annealing. Strong cracking inside the carbide layer near the failure area was observed in the case of sample with the thickest tungsten carbide layer formed.

The results obtained provide a basis for estimating the operation time for $\mathrm{W}$ coated plasma facing components in a nuclear fusion device. In order to facilitate a quantitative prediction for variable temperatures experiments at different annealing temperatures are now in progress.

\section{Acknowledgment}

This work financially supported by Polish Ministry of Science and Higher Education (contract number 0344/T02/2010/70). 


\section{$\underline{\text { References }}$}

1. N. Holtkamp; Fusion Eng. Des. 84 (2009) 98-105

2. R.A. Pitts, S. Carpentier, F. Escourbiac, T. Hirai, V. Komarov, A.S. Kukushkin, S. Lisgo, A. Loarze, M. Merola, R. Mitteau, A.R. Raffray, M. Shimada, P.C. Stangeby, J. Nucl. Mater. (2011), doi:10.1016/j.jnucmat.2011.01.114

3. M. Shimada, R. Pitts, A. Loarte, D.J. Campbell, M. Sugihara, V. Mukhovatov, A. Kukushkin, V. Chuyanov, J. Nucl. Mater. 390-391 (2009) 282

4. V. Philipps, Ph. Mertens, G.F. Matthews, H. Maier, JET-EFDA contributors, Fusion Eng. Des. 85 (2010) 1581

5. J. Pamela, G.F. Matthews, V. Philipps, R. Kamendje, JET-EFDA Contributors, J. Nucl. Mater. 363-365 (2007) 1

6. G. Piazza, G.F. Matthews, J. Pamela, H. Altmann, J.P. Coad, T. Hirai, A. Lioure, H. Maier, Ph. Mertens, V. Philipps, V. Riccardo, M. Rubel, E. Villedieu, Collaborators of the JET ITER-like Project, J. Nucl. Mater. 367-370 (2007) 1438

7. T. Hirai, H. Maier, M. Rubel, Ph. Mertens, R. Neu, E. Gauthier, J. Likonen, C. Lungu, G. Maddaluno, G.F. Matthews, R. Mitteau, O. Neubauer, G. Piazza, V.Philipps, B. Riccardi, C. Ruset, I. Uytdenhouwen, Fusion Eng. Des. 82 (2007) 1839

8. H. Maier, R. Neu, H. Greuner, Ch. Hopf, G.F. Matthews, G. Piazza, T. Hirai, G. Counsell, X. Courtois, R. Mitteau, E. Gauthier, J. Likonen, G. Maddaluno, V. Philipps, B. Riccardi, C. Ruset, EFDA-JET Team, J. Nucl. Mater. 363-365 (2007) 1246

9. H. Maier, R. Neu, H. Greuner, B. Böswirth, M. Balden, S. Lindig, G.F. Matthews, M. Rasinski, P. Wienhold, A. Wiltner, Phys. Scr. T138 (2009) 14031 
10. G.F. Matthews, P. Coad, H. Greuner, M. Hill, T. Hirai, J. Likonen, H. Maier, M. Mayer, R. Neu, V. Philipps, R. Pitts, V. Riccardo, JET EFDA Contributors, J. Nucl. Mater 390-391 (2009) 934

11. C. Ruset, E. Grigore, I. Munteanu, H. Maier, H. Greuner, C. Hopf, V. Philipps, G.F. Matthews, JET-EFDA Contributors, Fusion Eng. Des. 84 (2009) 1662

12. H. Maier, M. Rasinski, E. Grigore, C. Ruset, H. Greuner, B. Böswirth, G.F. Matthews, M. Balden, S. Lindig, J. Nucl. Mater. 415 (2011) S310

13. T.B. Massalski (Ed), Binary Phase Diagrams, TMS, 1992

14. K.M. Reddy, T.N. Rao, J. Joardar, Materials Chemistry and Physics 128 (2011) 121126

15. S. L. Kharatyan, H.A. Chatilyan, L.H. Arakelyan, Materials Research Bulletin, 43 (2008) 897

16. N. Keller, B. Pietruszka, V. Keller, Materials Letters 60 (2006) 1774

17. Y. L. Corcoran, A. H. King, N. de Lanerolle, B. Kim, Journal of Electronic Materials 19 (1990) 1177

18. Y. Tanaka, M. Kajihara, Y. Watanabe, Materials Science and Engineering A 445-446 (2007) 355-363 


\section{Figure caption}

Figure 1

Cross-section SEM images of the coatings: as-deposited (a) and after annealing at $1470 \mathrm{~K}$ for $0.5 \mathrm{~h}(\mathrm{~b}), 1 \mathrm{~h}(\mathrm{c}), 2 \mathrm{~h}(\mathrm{~d}), 5 \mathrm{~h}(\mathrm{e})$ and $20 \mathrm{~h}(\mathrm{f})$

Figure 2 TEM image of FIB prepared lamella of the deposited coatings after a) $0.5 \mathrm{~h}$ annealing at $1470 \mathrm{~K}$, b) $20 \mathrm{~h}$ annealing at $1470 \mathrm{~K}$, both with diffraction phase analysis

Figure 3

The average thickness of WC (black) and total tungsten carbide $\left(\mathrm{WC}+\mathrm{W}_{2} \mathrm{C}\right)(\mathrm{red})$ layer Figure 4

Cross-section SEM images of the coatings: as-deposited (a) and after annealing at $1470 \mathrm{~K}$ for

$2 \mathrm{~h}(\mathrm{~b}), 5 \mathrm{~h}(\mathrm{c})$ and $20 \mathrm{~h}(\mathrm{~d})$ all after the micro scratch test. Additionally the local force of scratch test is indicated. 
Figure 1 single column
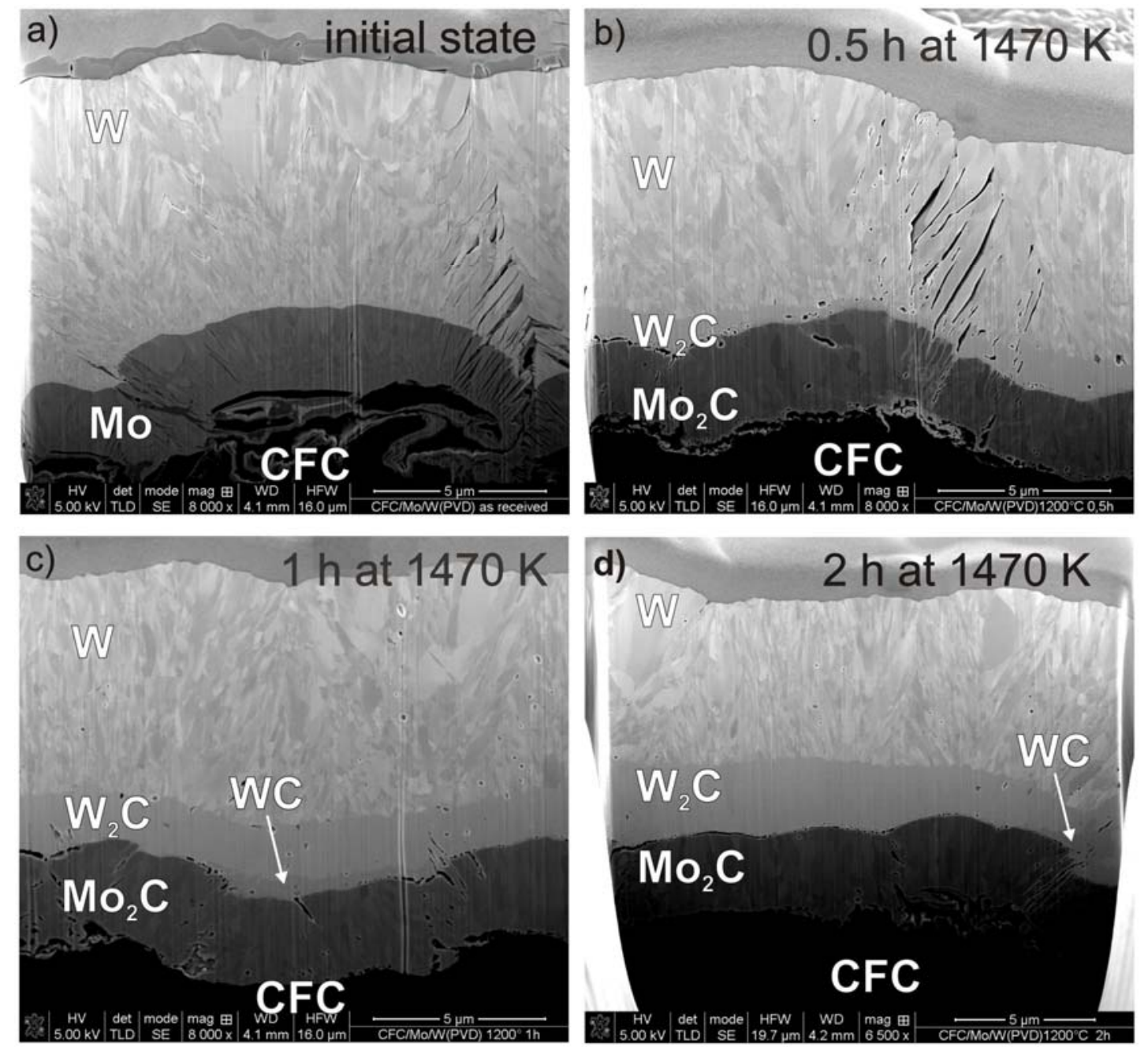

e)
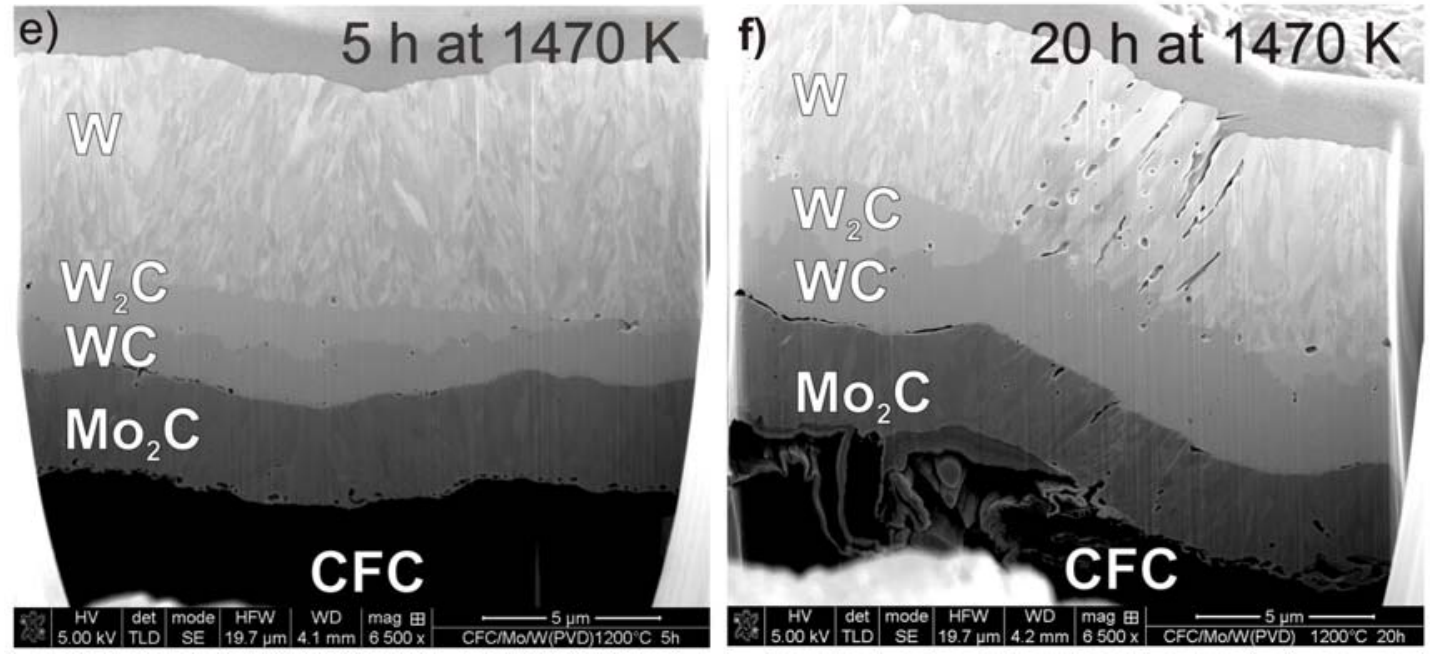
Figure 2 double column

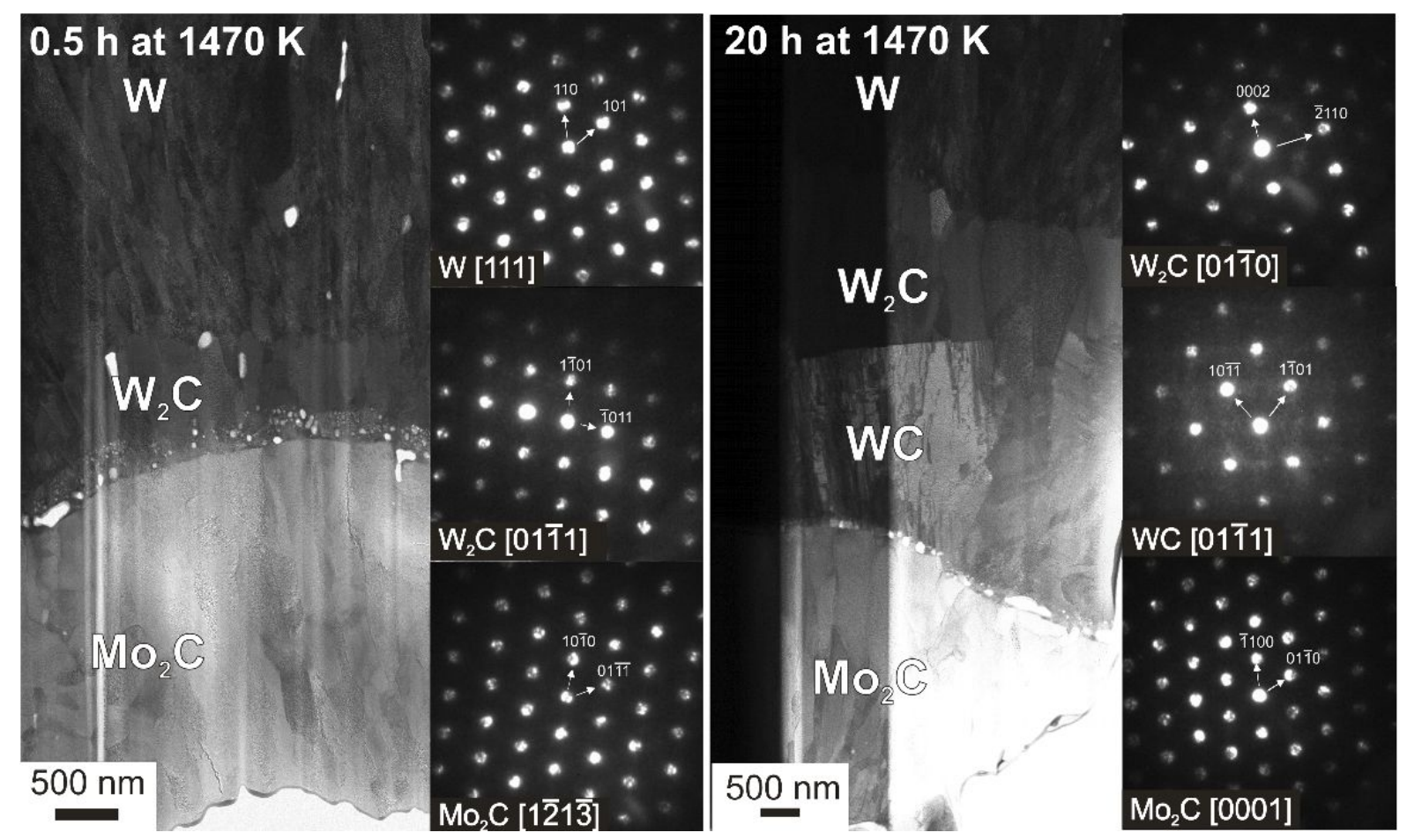

Figure 3 single column

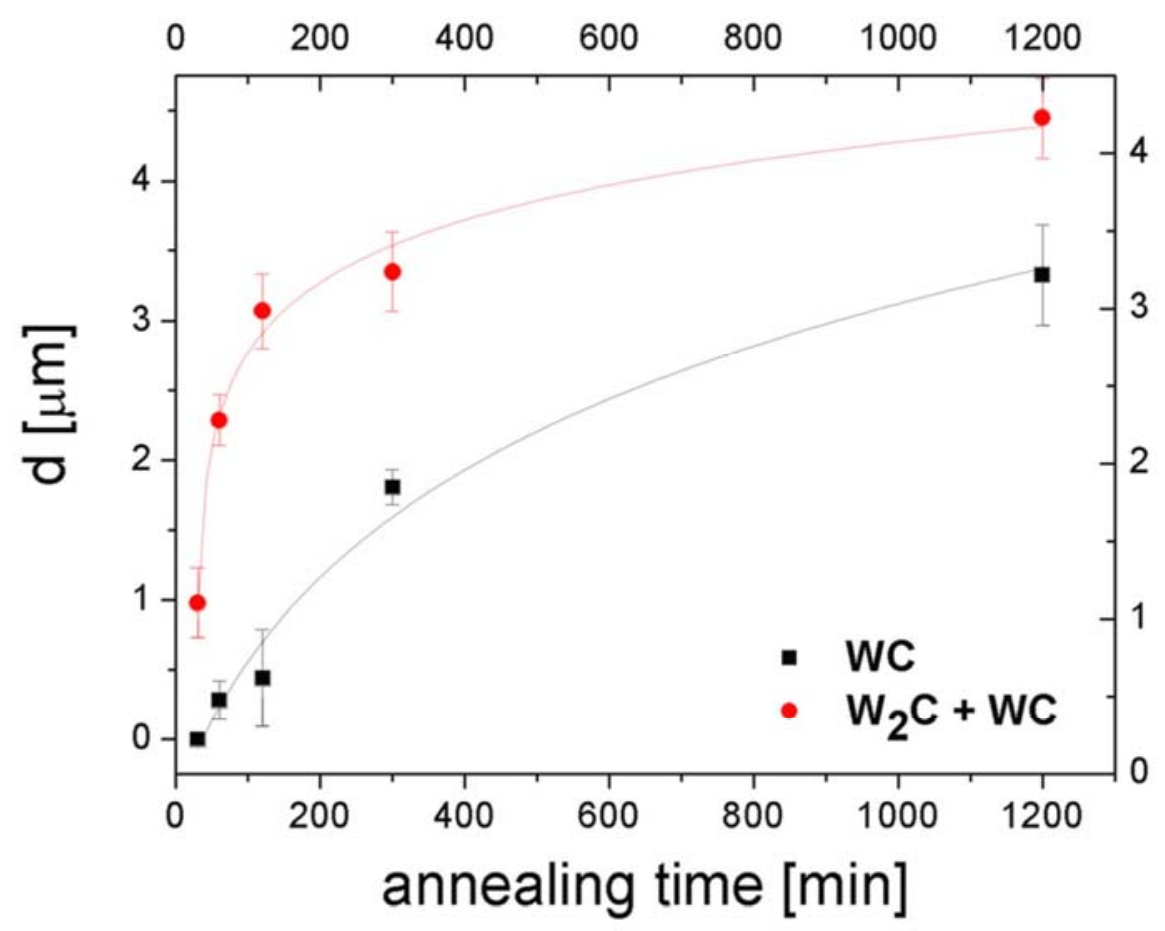


Figure 4 single column

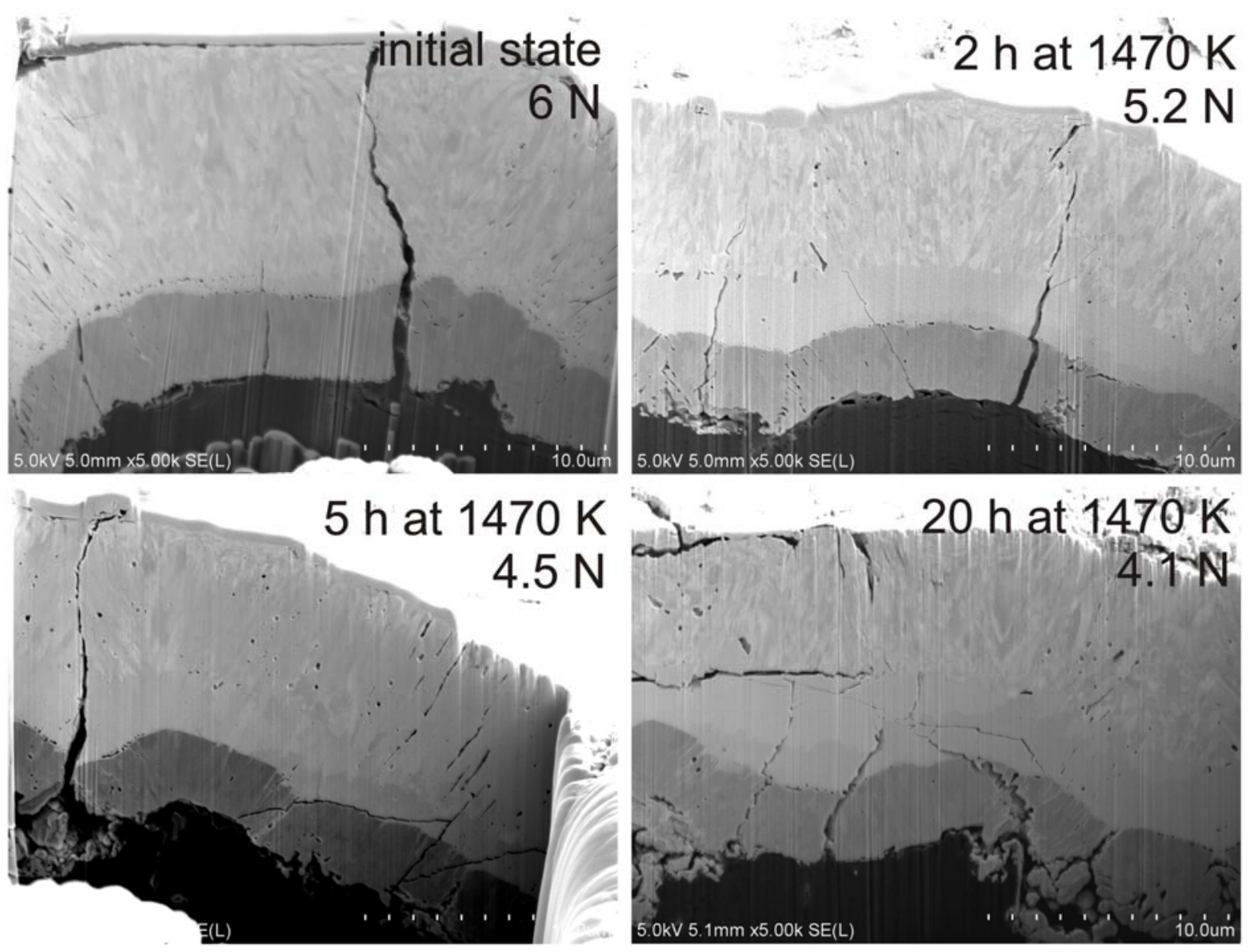

